\title{
Preference for wine is associated with lower hip fracture incidence in post-menopausal women
}

\author{
Jessica T Kubo ${ }^{*}$, Marcia L Stefanick ${ }^{2}$, John Robbins ${ }^{3}$, Jean Wactawski-Wende ${ }^{4}$, Mark R Cullen ${ }^{5}$, \\ Matthew Freiberg ${ }^{6}$ and Manisha Desai ${ }^{1}$
}

\begin{abstract}
Background: Past studies of relationships between alcohol and hip fracture have generally focused on total alcohol consumed and not type of alcohol. Different types of alcohol consist of varying components which may affect risk of hip fracture differentially. This study seeks to examine the relationship between alcohol consumption, with a focus on type of alcohol consumed (e.g. beer, wine, or hard liquor) and hip fracture risk in post-menopausal women.
\end{abstract}

Methods: The longitudinal cohort consisted of U.S. post-menopausal women aged 50-79 years enrolled between 1993-1998 in the Women's Health Initiative Clinical Trials and Observational Study ( $N=115,655)$.

Results: Women were categorized as non-drinkers, past drinkers, infrequent drinkers and drinkers by preference of alcohol type (i.e. those who preferred wine, beer, hard liquor, or who had no strong preference). Mean alcohol consumption among current drinkers was 3.3 servings per week; this was similar among those who preferred wine, beer and liquor. After adjustment for potential confounders, alcohol preference was strongly correlated with hip fracture risk ( $p=0.0167)$; in particular, women who preferred wine were at lower risk than non-drinkers $(\mathrm{OR}=0.78$; 95\% Cl 0.64-0.95), past drinkers ( $\mathrm{OR}=0.85 ; 95 \% \mathrm{Cl} 0.72-1.00)$, infrequent drinkers ( $\mathrm{OR}=0.73 ; 95 \% \mathrm{Cl} 0.61-0.88)$, hard liquor drinkers ( $\mathrm{OR}=0.87 ; 95 \% \mathrm{Cl} 0.71-1.06)$, beer drinkers ( $\mathrm{OR}=0.72 ; 95 \% \mathrm{Cl} 0.55-0.95)$ and those with no strong preference $(\mathrm{OR}=0.89 ; 95 \% \mathrm{Cl} 0.89 ; 95 \% \mathrm{Cl} 0.73-1.10)$.

Conclusions: Preference of alcohol type was associated with hip fracture; women who preferentially consumed wine had a lower risk of hip fracture compared to non-drinkers, past drinkers, and those with other alcohol preferences.

Keywords: Alcohol, Wine, Hip fracture, Osteoporosis, Women's Health Initiative

\section{Background}

Hip fractures are a major public health problem worldwide [1], contributing to decreased quality of life and premature death [1-6]. In the United States, over 280,000 people over the age of 65 experienced a hip fracture in 2007 [5]. In 2005, the estimated total cost of hip fractures in the US was $\$ 12$ billion and was estimated to increase $50 \%$ by 2025 [7]. More than two-thirds of all hip fractures occur in women $[5,8]$ and older age significantly increases the risk of fracture $[5,9,10]$ with those 85 and older having a ten-fold risk compared to those who are 60-65 [5].

\footnotetext{
* Correspondence: jkubo@stanford.edu

'Quantitative Sciences Unit, Stanford University School of Medicine, 1070

Arastradero Road, Palo Alto, Stanford, CA 94304, USA

Full list of author information is available at the end of the article
}

Other factors known to be associated with hip fracture incidence include low body mass index [11], European or Asian race/ethnicity [12,13], smoking [14,15] and less physical activity $[2,13,16]$. A previous analysis of Women's Health Initiative (WHI) Observational Study (OS) data identified each of these factors as important predictors of hip fracture [17].

Light-to-moderate alcohol consumption has been shown to be associated with reduced risk of hip fracture and increased bone density [18-22]. More precisely, a U-shaped relationship has been observed in which non-drinkers and heavy drinkers have an elevated risk of hip fracture compared to light-moderate drinkers. The 2010 Dietary Guidelines for Americans defines moderate alcohol consumption as up to one drink per day for women [23].

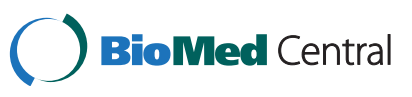


While various studies suggest that alcohol consumption may be related to hip fracture, the risk of hip fracture may be different for those who consume beer, wine, and hard liquor as was observed for cardiovascular disease [24,25] and overall mortality [24-28]. In a study of 31,785 men and women in Denmark, Høidrup et al. [19] assessed preference of alcohol type among current alcohol consumers and found that those who preferred wine had a reduced risk of hip fracture compared to those who preferred beer or liquor. In contrast, in their analysis of the Cardiovascular Health Study, Mukamal et al. [20] found that the reported consumption of beer, wine and hard liquor did not have a significant association with hazard of hip fracture. The discrepancy may be due to differences in the populations studied; Høidrup et al. studied Danish adults and Mukamal studied US adults over 65 from four communities. Another possible reason for the discrepancy may lie in how the exposure variable was defined. Whereas Høidrup et al. modeled alcohol preference, Mukamal et al. modeled consumption of type using indicator variables. Our study seeks to reconcile inconsistencies in past studies of alcohol preference and to take past drinkers and non-drinkers into account. We will investigate the relationship between type of alcohol consumed and the risk of hip fracture in a large, ethnically and geographically diverse cohort of postmenopausal women in the United States with available data on potentially important confounders of the relationship including physical activity and falls.

\section{Methods}

The question of interest was addressed using a large multi-ethnic cohort of postmenopausal women enrolled in either the Women's Health Initiative (WHI) Clinical Trials (CT, $\mathrm{N}=68,133$ ) or the Observational Study (OS, $\mathrm{N}=93,676)$ at 40 clinical centers across the United States between 1993 and 1998. The CT enrolled participants into one or more clinical trial components: the Hormone Therapy Trials, Dietary Modification Trial, or Calcium/ Vitamin D Trial; those ineligible or unwilling to participate in the CT were invited to enroll in the OS, which also enrolled participants directly [29]. Closeout occurred from 2004-2005 for the main study. Study design and eligibility have been described previously [30]. The analysis was based on a cohort that included all eligible WHI participants in the CT and OS. The study was approved by Institutional Review Boards at each clinical center. All participants provided signed informed consent.

Figure 1 describes the derivation of the cohort. Eligible participants were those with data on alcohol consumption, with no history of cancer, and no evidence of hip replacement at baseline. Participants were considered ineligible if they were missing relevant data collection forms. There were 142,224 participants eligible for study.
Due to missing covariates included in the scientific model, 26,569 were further excluded, yielding a final analytic data set of $\mathrm{N}=115,655$ (15.2\% missing).

Exclusions were largely due to missing data on prior hip fractures and parental hip fractures, both of which were not collected on forms for all participants. Underlying reasons for missing the latter, therefore, are unlikely to be related to participant characteristics. Some systematic differences were observed, however, between those participants who were excluded due to missing data $(\mathrm{N}=26,569)$ and those included in the analysis $(\mathrm{N}=115,655)$. For example, a higher proportion of white women were included in the analysis than among those excluded (83.65\% versus $77.25 \%)$. Other differences included the percentage of falls $(68.81 \%$ of those who were included reported no falls, compared to $61.29 \%$ of those who were excluded), and percentage of participants included in the OS cohort (57.70\% compared to $45.77 \%$ ). Rates of incident hip fracture, however, did not differ by inclusion status.

\section{Covariates}

Type of alcohol consumed was measured in two ways. The first was a categorical variable that captured preference of type of alcohol. The second consisted of three nonmutually exclusive indicator variables for whether a specific type of alcohol was consumed, where the possibilities included beer, wine, and hard liquor. More specifically, for the former, seven mutually exclusive categories of alcohol preference were created; non-drinker, past drinker, and current drinkers who prefer beer, wine, hard liquor, have no strong preference, or drink very infrequently, as determined by food frequency questionnaire (FFQ) consumption patterns of beer, wine, and hard liquor at baseline. Current-beer was assigned to those whose beer consumption constituted 60 or more percent of their total alcohol consumption. Current-wine and currenthard liquor preference were defined similarly. Current-no strong preference was assigned to those who did not have a predominating type of alcohol. A participant was classified as current-infrequent if the participant reported being a current drinker but did not report consumption on their FFQ. The WHI FFQ was validated for alcohol consumption using four day food records and four day diet recalls [31].

\section{Hip fracture}

The primary outcome was an indicator for having a hip fracture during the WHI study period. Hip fractures were centrally adjudicated at the WHI Bone Density Center by a physical adjudicator; participants reporting a hip fracture on the semi-annual (CT) or annual (OS) medical history update were contacted for additional information and medical records [32,33]. 


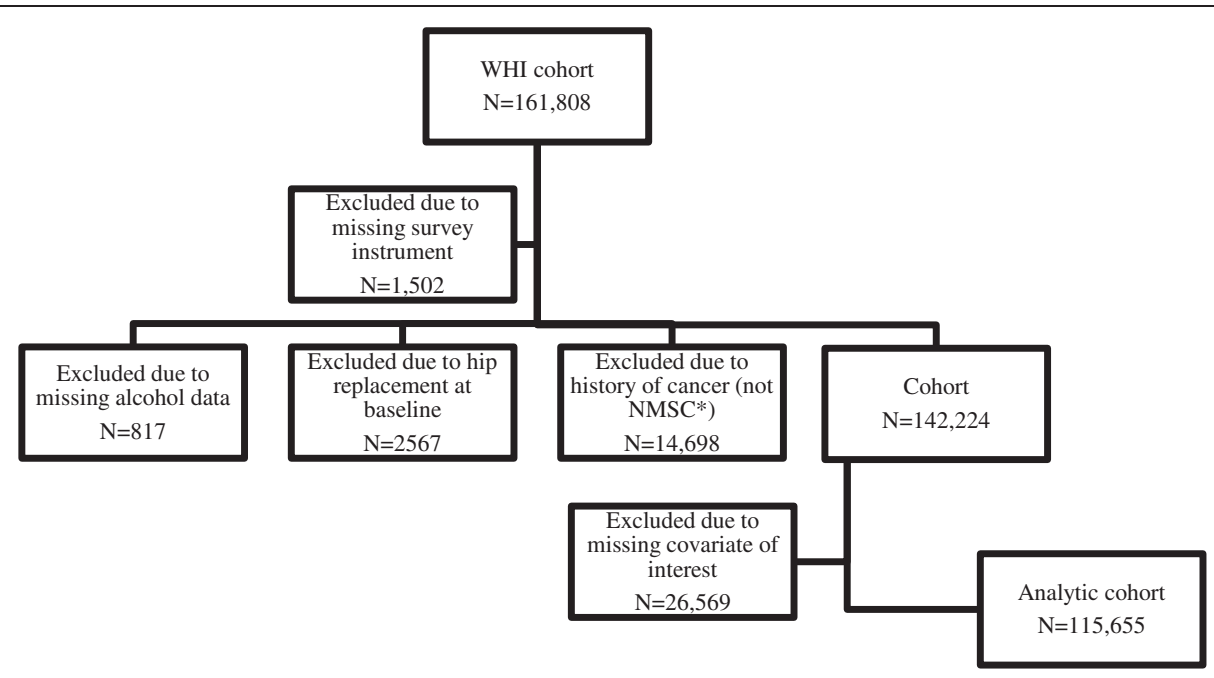

Figure 1 Construction of the analytic cohort. ${ }^{*}$ NMSC: Non-melanoma skin cancer.

Adjustments were made for potential confounders as identified by prior analyses of hip fracture in the WHI and other cohorts as well as for clinically important variables. Demographic factors included race/ethnicity, age group and education at screening. Also included was a diagnosis of osteoporosis, bisphosphonate drug use, previous hip fracture at age 55 and up, and history of hip fracture at age 40 and up for either parent from participant medical history. Baseline risk factors included smoking status, hormone therapy use, physical activity in metabolic equivalents per week, BMI category as defined by WHO, and the number of falls the participant reported in the past year. All covariates were measured at baseline. We also included indicators for the relevant trial arms as defined by the WHI.

\section{Statistical analyses}

The relationship between alcohol preference (modeled as a categorical variable) and risk of hip fracture was assessed using logistic regression methods. An alternative model that made use of indicators for each type of alcohol allowed investigation of associations between types of alcohol and risk of hip fracture as opposed to preference of alcohol type. Odds ratios that describe the association are presented after adjusting for listed confounders. Additionally, several covariates (falls in the past year, BMI, education and age) were explored as potential mediators and moderators of the relationship between alcohol consumption and hip fracture. Total alcohol consumption was also explored as a confounder.

As the CT and OS populations differ slightly, the two study cohorts were additionally analyzed separately as a sensitivity analysis. Data on red and white wine consumption were available in the OS cohort at year 1 of follow up; to explore differences between red and white wine those who preferred wine were additionally split based on whether they reported higher consumption of red wine, higher consumption of white wine, or equal consumption of red and white wine. Several additional sensitivity analyses were performed; in the first, participants reporting a prior hip fracture at baseline were excluded from analysis. The second excluded participants who reported having osteoporosis at baseline. A final sensitivity analysis, for the indicator model, defined alcohol use for moderate drinkers only ( $>1$ drink/day) in accordance with the 2010 Dietary Guidelines for Americans [23]. All analyses were performed with SAS software, Version 9.3 (SAS Institute Inc., Cary, NC) of the SAS System for Windows.

\section{Results}

Table 1 presents baseline characteristics of the 115,655 women in the analytic cohort. On average they were 63.1 years old at study entry and $83.7 \%$ were white. Approximately $11.1 \%$ were non-drinkers, $18.0 \%$ were past drinkers and of the current drinkers, $47.4 \%$ preferred wine, $6.6 \%$ preferred beer, $12.7 \%$ preferred hard liquor, $15.7 \%$ had no strong preference, and $17.7 \%$ drank infrequently. Strong associations between baseline characteristics and preference of type of alcohol were observed. For example, $86.9 \%$ of non-drinkers also reported never having smoked whereas only $40.0 \%$ of the beer drinkers never smoked. In addition, wine drinkers reported more physical activity than any other category of alcohol preference. Only $1.3 \%$ of nondrinkers experienced a hip fracture during the follow up period, whereas percentages were even lower for all current alcohol consumer types with the exception of hard liquor drinkers (1.4\%) and past consumers (1.2\%) (Figure 2).

Consumption of alcohol was comparable across type of preference and relatively low (mean: 3.34 servings per 
Table 1 Baseline demographic and risk factor characteristics by alcohol type preference in the WHI OS+CT cohort

\begin{tabular}{|c|c|c|c|c|c|c|c|c|c|}
\hline \multirow[t]{2}{*}{ Covariate } & \multicolumn{7}{|c|}{ Drinker type classification } & \multirow[t]{2}{*}{ Total } & \multirow[t]{2}{*}{$x^{2} p$-value } \\
\hline & Prefer beer & Prefer liquor & $\begin{array}{l}\text { No } \\
\text { preference }\end{array}$ & $\begin{array}{l}\text { Infrequent } \\
\text { drinker }\end{array}$ & Prefer wine & Non-drinker & Past drinker & & \\
\hline Cohort & 54054.7 & 104129.0 & 1287611.1 & 1448312.5 & 3884133.6 & 1280511.1 & 2083318.0 & 115655 & \\
\hline
\end{tabular}

\section{Characteristics at baseline}

Ethnicity

American Indian or Alaskan

Native

Asian or Pacific Islander $\quad 104$

1.9

Black or African-American $\quad 566$

10.5

Hispanic/Latino

$$
370
$$$$
6.9
$$

White (not of Hispanic origin) 4271

Other

$$
79.0
$$$$
65
$$$$
1.2
$$

Age group at screening

$<50-59$

60-69

70-79+

Education

High school or less

Some college/AA

College/post sec.

Osteoporosis

No

Yes

$$
5104
$$

94.4

$$
301
$$

5.6

Number of falls in the past 12 months

None

1 time

2 times

$\begin{array}{ll}3727 & 7256 \\ 69.0 & 69.7 \\ 1035 & 2009 \\ 19.2 & 19.3 \\ 425 & 804 \\ 7.9 & 7.7\end{array}$

33
0.3
66

$$
0.6
$$$$
636
$$$$
6.1
$$$$
190
$$

1.8

$$
9407
$$$$
90.4
$$$$
80
$$$$
0.8
$$

2819

27.1

4917

$$
47.2
$$$$
2676
$$$$
25.7
$$

3171

$$
30.5
$$$$
3040
$$

$$
29.2
$$$$
4201
$$$$
40.4
$$

\section{8}

$$
93.6
$$$$
664
$$

$$
6.4
$$$$
7.7
$$

$\begin{array}{ll}42 & 53 \\ 0.3 & 0.4 \\ 141 & 482 \\ 1.1 & 3.3\end{array}$

$\begin{array}{ll}693 & 1256 \\ 5.4 & 8.7\end{array}$

400

$$
588
$$

4.1

11495

11923

82.3

105

0.8

181

1.3

4981

38.7

5709

44.3

2186

17.0

5467

37.8

6324

43.7

2692

18.6

3234

25.1

3575

27.8

6067

47.1

5044

34.8

4306

29.7

5133

35.4

12148

94.4

728

5.7

13566

93.7

917

6.3

$8670 \quad 9962$

67.3

2622

20.4

1104

8.6

68.8

2830

19.5

1166

8.1

\begin{abstract}
100
\end{abstract}

$$
0.3
$$$$
581
$$

$$
1.5
$$$$
1636
$$$$
4.2
$$$$
955
$$$$
2.5
$$$$
35193
$$$$
90.6
$$$$
376
$$$$
1.0
$$

376
1.0

\section{9}

34.5

17772

45.8

7690

19.8

8858

22.8

10568

27.2

19415

50.0

36291

93.4

2550

6.6

26733

68.8

7825

20.2

2973

7.7

7

7

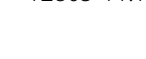

$<.0001$

$\begin{array}{lll}78 & 116 & 451 \\ 0.6 & 0.6 & \\ 1253 & 660 & 3287 \\ 9.8 & 3.2 & \end{array}$

$1702 \quad 3098$

$13.3 \quad 14.9$

$829 \quad 980$

$6.5 \quad 4.7$

$8741 \quad 15710 \quad 96740$

$68.3 \quad 75.4$

$202 \quad 269$

$1.6 \quad 1.3$

9587

4312

1.3

1278

3523

6667
32.0
9384
45.0
4782
23.0

$<.0001$

39087

$27.5 \quad 32.0$

$5896 \quad 9384$

52357

$46.0 \quad 45.0$

$\begin{array}{ll}3386 & 4782 \\ 26.4 & 23.0\end{array}$

24211

(26.4

5835

8625

$45.6 \quad 41.4$

3009

5708

$23.5 \quad 27.4$

3961

6500

31.2

$<.0001$

$30.9 \quad 31.2$

47234

$<.0001$

36805

31616

47234

$\begin{array}{lll}11726 & 19075 & 107658 \\ 91.6 & 91.6 & \end{array}$

$\begin{array}{ll}91.6 & 91.6 \\ 1079 & 1758 \\ 8.4 & 8.4\end{array}$

7997

$\begin{array}{ll}8.4 & 8.4\end{array}$

8.4

9013

14223

68.3

3990

19.2

18.3

1682

$\begin{array}{ll}7.5 & 8.1\end{array}$ 
Table 1 Baseline demographic and risk factor characteristics by alcohol type preference in the WHI OS+CT cohort (Continued)

3 or more times

\author{
218

343

4.0

3.3

3.3

Prior hip fracture at baseline at age 55+

No

Yes

5391

99.7

14

0.3

Parent had hip fracture at age 55+

No

Yes

$$
4763
$$

88.1

642

11.9

On bisphosphonate medication at screening

No

Yes

$$
5328
$$

98.6

77

1.4

Amount of alcohol consumption

Servings per week

$\begin{array}{ll}4.2 & 6.1 \\ 6.3 & 7.3\end{array}$

Category of alcohol consumption

Non-drinker

0
0.0

Past drinker

Past dinker

$<1$ drink per month

$<1$ drink per week

$1-<7$ drinks per week

$7+$ drinks per week

Smoking status

Never Smoked

Past Smoker

Current Smoker

0.0

0.0

0.0

0

0.0

1832

$$
33.9
$$

2580

47.7

993

18.4

0

0.0

0

0.0

0

0.0

2373

22.8

4549

43.7

3490

33.5

$$
2161
$$

3677

$$
40.0
$$

$$
35.3
$$

2623

5306

48.5

51.0

621

11.5

1429

13.7

HT Use

Never used

$\begin{array}{ll}2451 & 4466 \\ 45.4 & 42.9\end{array}$

$\begin{array}{ll}480 & 525 \\ 3.7 & 3.6 \\ & \\ 12849 & 14441 \\ 99.8 & 99.7 \\ 27 & 42 \\ 0.2 & 0.3\end{array}$

1310

3.4

496

3.9

938

4.5

38723

99.7

12757
99.6
48
0.4

118

0.3

0.4

33545

11212

$$
86.4
$$$$
87.6
$$$$
1593
$$$$
12.4
$$$$
5296
$$

13.6

12.4

38020

12540

97.9

265

2.1

$$
2.1
$$

3.7

5.2

0
0.0

0

0.0

$\begin{array}{ll}12805 & 0 \\ 100.0 & 0.0 \\ 0 & 20833\end{array}$

$\begin{array}{lll}0 & 0 & 20833\end{array}$

20744

99.6

89

0.4

$<.0001$

$18303 \quad 100583$

87.9

2530

15072

12.1

$<.0001$

113557

20481

352

1.7

2098

0.0193

115280

375

00583 
Table 1 Baseline demographic and risk factor characteristics by alcohol type preference in the WHI OS+CT cohort (Continued)

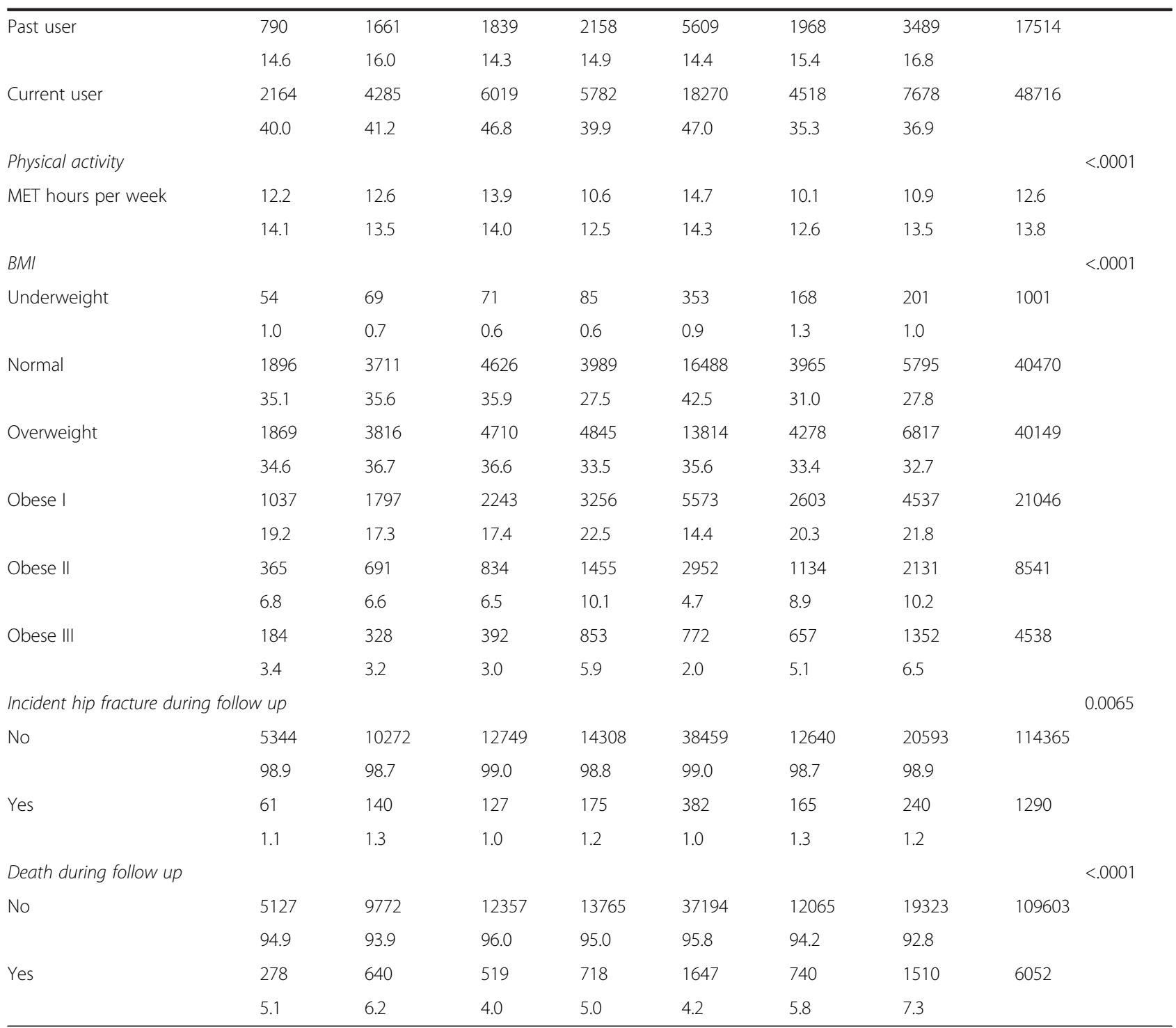

Note: counts and percentages are presented for categorical variables; means and standard deviations are presented for continuous variables.

week, SD: 5.46 among those reporting current alcohol consumption). Of those who prefer beer, average consumption was half a medium serving per day; this was also true for those who prefer wine. Those with a preference for hard liquor consumed three-fourths of a medium serving each day on average.

Preference of type of alcohol at baseline was strongly associated with risk of hip fracture $(\mathrm{p}=0.0167)$. Preferring wine was associated with $22 \%$ fewer hip fractures compared to non-drinkers; no other category was significantly different from non-drinkers. Further, wine drinkers experienced a reduced risk of hip fracture compared to beer drinkers $(\mathrm{OR}=0.72 ; 95 \%$ CI 0.55-0.95), hard liquor drinkers $(\mathrm{OR}=0.87 ; 95 \% \mathrm{CI} 0.71-1.06)$, those with no strong preference $(\mathrm{OR}=0.89 ; 95 \% \mathrm{CI} 0.73-1.10)$, infrequent drinkers (OR=0.73; 95\% CI 0.61-0.88), and past consumers (OR=0.85; 95\% CI 0.72-1.00). Asian, Black, and Hispanic women had a lower risk of hip fracture compared to white women; increasing age greatly increased the risk of hip fracture. Other risk factors for hip fracture included having osteoporosis, increasing number of falls in the past year, lower BMI category, less physical activity, current smoking, never using hormone therapy (HT), having a previous hip fracture at age $55+$, and having a parent who fractured her or his hip at age 40+ (Table 2). When categories of current drinkers were combined, current drinkers had a $12.2 \%$ lower risk of hip compared to nondrinkers ( $p$-value $=0.3510$, not shown).

To evaluate whether specific types of alcohol consumed (beer, wine or hard liquor) are associated with 


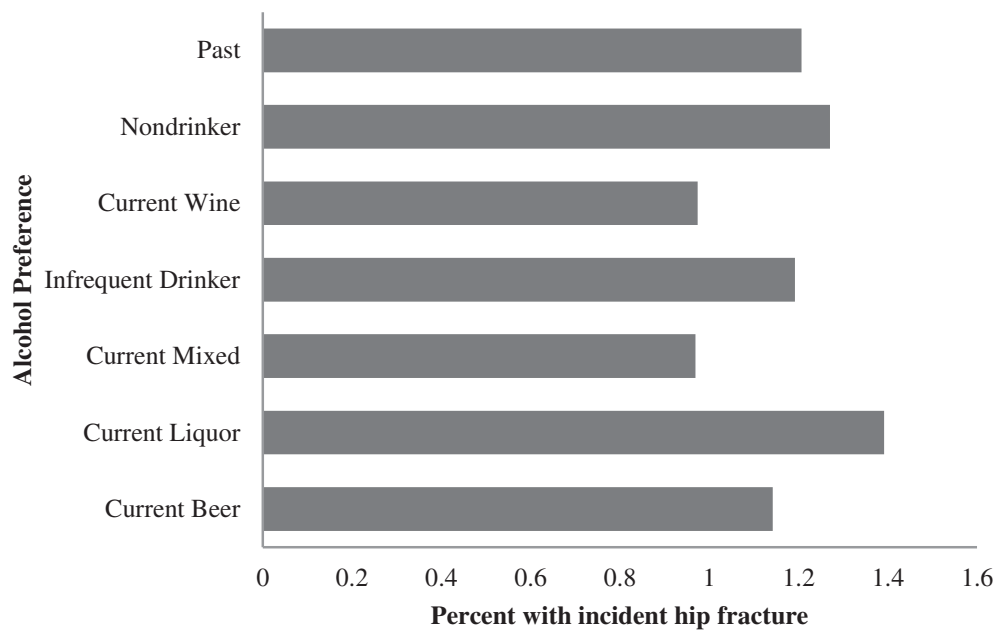

Figure 2 Percent of participants with incident hip fracture during the study period.

risk of hip fracture, indicator values were incorporated. Specifically, indicators for consuming at least one serving of beer per week, consuming at least one serving of wine per week, and consuming at least one serving of hard liquor per week were jointly included in the model. Whereas no association was observed between beer consumption or hard liquor consumption and risk of hip fracture, a protective association was observed for wine, where the odds ratio of 0.75 (95\% CI 0.64-0.87) suggested that wine drinkers have a $25 \%$ reduction in the risk of hip fracture after adjusting for consumption of other alcohol types and other confounders (Table 3).

To investigate the potential effect of amount of alcohol consumed, total alcohol servings per week was explored as a confounder both categorically and continuously. Total amount consumed was not significantly associated with hip fracture (category: $\mathrm{p}=0.6827$, amount: $\mathrm{p}=0.8162$ ), nor did it affect the coefficients corresponding to alcohol preference. Due to the low consumption in this cohort, the U-shaped relationship with hip fracture was not observed.

Age at menopause and dietary covariates for fruit, vegetable, fiber and dairy consumption were not included in the final models, as they did not change the coefficients corresponding to the covariate of interest and were not associated with hip fracture in exploratory analyses. The number of falls in the past year was explored as a potential moderator. A test for an interaction effect between falls and alcohol preference was not rejected ( $p$-value $=0.5846)$, suggesting that falls do not moderate the relationship between alcohol preference and hip fracture. Falls were also explored as a potential mediator; models fit with and without falls did not attenuate the effect of alcohol preference or change the point estimates for alcohol preference in a meaningful way. Additionally, there was not sufficient evidence to suggest the BMI modified the association between type of preference and hip fracture $(\mathrm{p}=0.7218)$. Interactions between preference and education $(\mathrm{p}=0.2301)$ and preference and age group $(\mathrm{p}=0.4120)$ were similarly not significant. We did not find evidence of effect modification by study cohort (CT and OS); further, when analyses were stratified by cohort, associations were in the same direction. Among the participants in the OS, those who preferred white wine, red wine, or both types had a lower risk of hip fracture compared to non-drinkers, however, this association was not significant $(\mathrm{p}=0.8731)$. In addition, indicators for more than one serving of red wine per week and more than one serving of white wine per week was not significant $(\mathrm{p}=0.6246$ and $\mathrm{p}=0.1124$ respectively).

\section{Sensitivity analyses}

To assess the influence of women with a prior hip fracture at baseline after age 55 on our findings, the analysis was repeated after excluding these women. The association of interest remained $(\mathrm{p}=0.0112$, OR for wine preference compared to non-drinkers $=0.76$; 95\% CI 0.62-0.92). Results were similar for the second sensitivity analysis, in which participants who reported having osteoporosis at baseline were excluded ( $\mathrm{p}=0.0071$, OR for wine preference compared to non-drinkers $=0.74 ; 95 \%$ CI $0.60-0.92)$. When indicators for beer, wine and liquor consumption were defined as more than 7 drinks per week in accordance with the 2010 Dietary Guidelines for Americans definition of moderate drinking, point estimates were in the same direction as the analysis defining consumption as more than 1 drink per week.

\section{Discussion}

We found compelling variation in risk of hip fracture by type of alcohol preference, where women who preferred wine appeared to have the lowest risk of hip fracture. In an alternative model, where the association of each type of 
Table 2 Associations between alcohol type preference and incident hip fracture in the WHI OS+CT cohort

\begin{tabular}{|c|c|c|c|c|}
\hline \multirow[t]{2}{*}{ Covariate } & \multicolumn{2}{|l|}{ Unadjusted model } & \multicolumn{2}{|l|}{ Adjusted model } \\
\hline & Odds ratio $(95 \% \mathrm{Cl})$ & P-value & Odds ratio $(95 \% \mathrm{Cl})$ & P-value \\
\hline Alcohol type preference & & $p=0.0067$ & & $p=0.0167$ \\
\hline Prefer beer vs. Non-drinker & $0.87(0.65,1.18)$ & & $1.07(0.79,1.46)$ & \\
\hline Prefer liquor vs. Non-drinker & $1.04(0.83,1.31)$ & & $0.90(0.71,1.14)$ & \\
\hline No strong preference vs. Non-drinker & $0.76(0.61,0.96)$ & & $0.87(0.68,1.11)$ & \\
\hline Infrequent drinker vs. Non-drinker & $0.94(0.76,1.16)$ & & $1.06(0.85,1.32)$ & \\
\hline Prefer wine vs. Non-drinker & $0.76(0.63,0.91)$ & & $0.78(0.64,0.95)$ & \\
\hline Past drinker vs. Non-drinker & $0.89(0.73,1.09)$ & & $0.92(0.75,1.13)$ & \\
\hline
\end{tabular}

Ethnicity

$p<.0001$

American Indian or Alaska Native vs. White

$0.81(0.30,2.18)$

Asian or Pacific Islander vs. White

$0.32(0.19,0.53)$

Black or African-American vs. White

$0.32(0.22,0.46)$

Hispanic or Latino vs. White

$0.31(0.17,0.55)$

Other vs. White

$0.51(0.25,1.02)$

Age group at screening

$p<.0001$

60-69 vs. 50-59

$2.78(2.25,3.45)$

70-79 vs. 50-59

$9.37(7.59,11.56)$

Education

$\mathrm{p}=0.8491$

HS vs. College

Some college vs. College

$1.04(0.91,1.19)$

$1.03(0.90,1.19)$

Osteoporosis at screening

$p<.0001$

No vs. Yes

$0.58(0.49,0.68)$

Falls in the past year

$1.15(1.00,1.32)$
$1.45(1.20,1.75)$
$2.13(1.69,2.68)$

$3+$ vs. None

Previous hip fracture at age 55+

No vs. Yes

$0.45(0.28,0.70)$

Parent had hip fracture at age $40+$

No vs. Yes

$0.68(0.59,0.78)$

Bisphosphonate drug at screening

No vs. Yes

$1.30(0.94,1.81)$

Smoking status

Current vs. Never

Past vs. Never

Hormone therapy status

Current vs. Never

Past vs. Never

Physical activity

METs per week

$1.42(1.15,1.77)$

$1.02(0.91,1.16)$

$p=0.0005$

MI Category

$0.65(0.57,0.74)$

$0.75(0.64,0.87)$

$0.99(0.98,0.99)$

$p<.0001$

Underweight vs. Normal

$1.98(1.37,2.85)$

Overweight vs. Normal

$0.67(0.58,0.76)$ 


\section{Table 2 Associations between alcohol type preference and incident hip fracture in the WHI OS+CT cohort (Continued)}

\begin{tabular}{lr}
\hline Obese I vs. Normal & $0.49(0.41,0.58)$ \\
Obese II vs. Normal & $0.52(0.40,0.68)$ \\
Obese III vs. Normal & $0.39(0.25,0.59)$
\end{tabular}

Table 2 is adjusted for alcohol type preference, ethnicity, age group, education, osteoporosis, falls in the past year, bisphosphonate drug use, smoking status, HT status, physical activity measured in MET hours, BMI category, HT trial arm, CaD trial arm, OS versus CT cohort, previous hip fracture at age $55+$, and parental history of hip fracture at age $40+$

alcohol consumed on risk of hip fracture was explored, we found that wine drinkers had a lower risk of hip fracture relative to those who did not report consuming wine at baseline.

We are not the first to investigate this question. In a Danish cohort consisting of 31,785 participants, Høidrup et al. found a significantly protective association with wine preference in age-, sex- and study-adjusted models, however the association did not persist after adjusting for BMI, smoking, physical activity, and education [19]. While our conclusions are similar, our study also found that the relationship between preferring wine compared to non-drinking and hip fracture was significant in a model adjusted for the same covariates and other important predictors of hip fracture including falls in the past year and history of hip fracture. Our results, however, are generalizable only to postmenopausal women and our cohort on average reported less alcohol consumption than the Danish cohort investigated by Høidrup.

Although their primary objective was assessing amount of alcohol consumed, Mukamal et al. also examined beer, wine, and liquor consumption in 5,865 participants in the Cardiovascular Health Study. They included 0 (reference), $<1,1-6$, and $7+$ drinks per week categories for beer, wine, and liquor and noted that no type was significantly associated with hip fracture [20]. The HR for 1-6 drinks per week of wine was 0.75 (95\% CI 0.48-1.17), which is similar to our finding that consumption of at least one serving of wine per week is associated with a reduction in risk of hip fracture of $25 \%$.
Previous studies have suggested that moderate alcohol consumption is protective in terms of hip fracture. For example, although they did not distinguish between type of alcohol consumed, Marrone et al. found a positive relationship between alcohol consumption and bone mineral density (BMD) of the hip in a cohort of postmenopausal women. They also found increased bone turnover in nondrinkers compared to those who drank alcohol [34].

Our analysis suggests that much of the relationship between alcohol and hip fracture may be due to wine consumption. There are likely to be many unidentified differences in individuals who prefer wine, beer or spirits. Mortensen et al. identified some of these factors [35].

Because of the observational nature of this analysis we can only speculate on the mechanisms of the associations we found. One possible explanation for this association is the resveratrol content in wine. In a study of bone loss in tail-suspended rats, resveratrol protected against bone loss during immobilization [36]. Resveratrol also acts as an inhibitor of adipogenesis and may potentially promote osteoblast formation [37].

Hip and other osteoporotic fractures often result from falls [2] and alcohol intake has been shown to influence falls [20,22]. The J-shaped pattern observed between amount of alcohol consumption and falls is similar to that observed with hip fractures [38], suggesting that falls may act as a mediator. We, however, found no evidence of an interaction between falls in the past year at baseline and alcohol preference on incident hip fracture; this suggests that the association of alcohol preference

Table 3 Associations between consumption of beer, wine and liquor and incident hip fracture in the WHI CT+OS cohort

\begin{tabular}{|c|c|c|c|c|}
\hline \multirow[b]{2}{*}{ Model } & \multicolumn{4}{|c|}{ Logistic model with alcohol consumption indicators } \\
\hline & HR (95\% Cl) & P-value & HR $(95 \% \mathrm{Cl})$ & P-value \\
\hline Consumes one or more servings of beer per week & & $p=0.8756$ & & $p=0.3267$ \\
\hline Beer, yes vs. no & $0.98(0.75,1.28)$ & & $1.14(0.88,1.49)$ & \\
\hline Consumes one or more servings of liquor per week & & $p=0.0004$ & & $p=0.4408$ \\
\hline Liquor, yes vs. no & $1.37(1.15,1.63)$ & & $1.07(0.90,1.28)$ & \\
\hline Consumes one or more servings of wine per week & & $p=0.0010$ & & $p=0.0002$ \\
\hline Wine, yes vs. no & $0.78(0.67,0.90)$ & & $0.75(0.64,0.87)$ & \\
\hline
\end{tabular}

Table 3 is adjusted for beer consumption, liquor consumption, wine consumption, ethnicity, age group, education, osteoporosis, falls in the past year, bisphosphonate drug use, smoking status, HT status, physical activity measured in MET hours, BMI category, HT trial arm, CaD trial arm, OS versus CT cohort, previous hip fracture at age $55+$, and parental history of hip fracture at age $40+$. 
does not vary between those who have and have not experienced falls. Furthermore, by comparing coefficients for preference of type of alcohol in models with and without an indicator for falling we examined whether falling is a possible pathway by which alcohol may affect hip fracture. As no attenuation of the association was observed between models, there was not sufficient evidence to indicate this as the case.

This analysis has a number of strengths; data are from a large ethnically and racially diverse cohort of postmenopausal women and contained a large number of hip fracture events. The outcome of interest, hip fracture, was centrally adjudicated by the WHI Clinical Coordinating Center. Further, the WHI collected many variables of interest in assessing hip fracture risk including falls, previous hip fractures, and family history of hip fracture that have not been fully evaluated in previous research.

There are several limitations as well. Preference of alcohol type was defined at baseline for each participant and does not capture lifetime consumption pattern, however, data from follow up assessments of beer, wine and hard liquor consumption suggest that preference does not change greatly (Figure 3 ).

Further, we are unable to classify past drinkers by type preference due to the lack of historical alcohol consumption data. Information on past alcohol preference would have allowed us to assess the effect of past preferences along with current preferences, which is of interest as alcohol preference tends to differ greatly for younger and older adults [39]. Also, preference of alcohol type was assigned based on reported alcohol consumption and on the food frequency questionnaire. However, in a subset of women in the WHI, FFQs were compared with four-day food records and 24-hour recalls; correlation between FFQ alcohol consumption and eight days of intake (four from recall, four from food records) was 0.86 for alcohol. The intra-class correlation coefficient for test-retest reliability for alcohol was 0.92 , suggesting that for this cohort alcohol consumption is adequately captured by FFQ [31].

Interestingly, total alcohol servings was explored as a confounder and not found to alter results. A possible explanation is that the overall variability for total alcohol consumed was low. Lack of variability in total amount consumed and low median alcohol intake in this cohort may affect the generalizability of our results. Also, as the FFQ did not ask participants the amounts of red and white wine consumed, we were unable to differentiate wine drinkers into red wine drinkers and white wine drinkers except in the OS cohort.

Our analysis did not account for varying lengths of follow up time. We also considered and fit Cox proportional hazards models, using adjudicated time to hip fracture and censored at the end of the main study, death, or last follow up visit. Findings were comparable based on this model. As hip fracture is a rare event $(<2 \%$ in the cohort during the study period) and follow-up time is comparable among women across the levels of the preference variable, our model choice of a logistic regression was justified.

Unmeasured confounders of the relationship between hip fracture and alcohol preference may exist. Although we attempted to account for socio-demographic covariates and dietary preferences by adjusting for education in the model, wine drinkers may differ by other endogenous characteristics or lifestyle factors that we did not observe. Further, other socioeconomic characteristics such as income [40,41], type of housing [40,42], living with someone [43] or deprivation [44] might have been important confounders even after adjusting for education. These

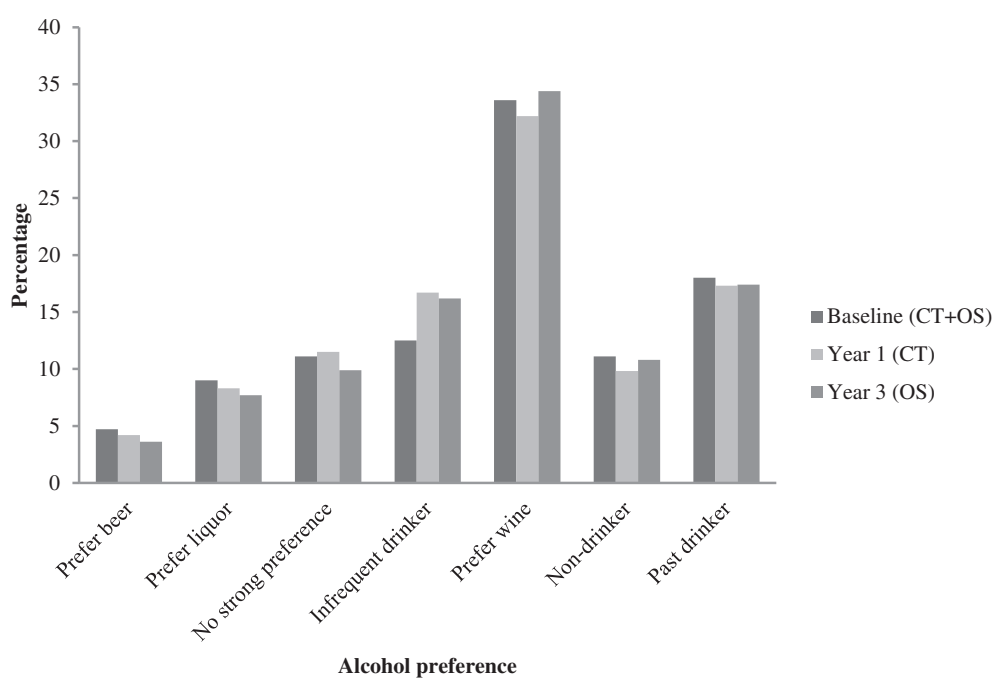

Figure 3 Alcohol preference at baseline (entire cohort, CT+OS), year 1 (CT only), and year 3 (OS only). 
characteristics are likely to be related to alcohol preference especially with regards to wine [35]. Finally, not having BMD measurements on this population limited us from investigating the role of alcohol type on bone density, one important mechanism to consider.

\section{Conclusions}

Postmenopausal women who are current alcohol consumers and prefer wine experience significantly fewer hip fractures compared to women who are non-drinkers, as well as those who prefer beer, those who prefer liquor, those with no strong preference, those who drink infrequently, and those who report being past alcohol consumers. The variability in risk of hip fracture by type of alcohol appears to be driven by the protective association seen here for wine drinkers. Note that these results generalize to a cohort of older women who are largely light drinkers and may not apply to men or moderate to heavy drinkers.

\section{Abbreviations}

WHI: Women's Health Initiative; CT: Clinical Trial; OS: Observational Study; FFQ: Food Frequency Questionnaire; BMD: Bone mineral density; HT: Hormone Therapy.

\section{Competing interests}

The authors have no conflicts of interest to report.

\section{Authors' contributions}

All authors contributed to this work. Specifically, JTK participated in designing the research plan, performed all statistical analyses and co-wrote the manuscript. MLS, JR, JWW, MRC and MF participated in designing the research plan, provided feedback on analyses, and edited the manuscript. MD participated in developing the research plan, directed the analyses and co-wrote the manuscript. All authors read and approved the final version of the manuscript for submission.

\section{Acknowledgments}

The authors would like to acknowledge the Women's Health Initiative investigators: Program Office: (National Heart, Lung, and Blood Institute, Bethesda, Maryland) Jacques Rossouw, Shari Ludlam, Dale Burwen, Joan McGowan, Leslie Ford, and Nancy Geller, Clinical Coordinating Center: Clinical Coordinating Center: (Fred Hutchinson Cancer Research Center, Seattle, WA) Garnet Anderson, Ross Prentice, Andrea LaCroix, and Charles Kooperberg Investigators and Academic Centers: (Brigham and Women's Hospital, Harvard Medical School, Boston, MA) JoAnn E. Manson; (MedStar Health Research Institute/Howard University, Washington, DC) Barbara V. Howard; (Stanford Prevention Research Center, Stanford, CA) Marcia L. Stefanick; (The Ohio State University, Columbus, OH) Rebecca Jackson; (University of Arizona, Tucson/Phoenix, AZ) Cynthia A. Thomson; (University at Buffalo, Buffalo, NY) Jean Wactawski-Wende; (University of Florida, Gainesville/Jacksonville, FL) Marian Limacher; (University of lowa, lowa City/Davenport, IA) Robert Wallace; (University of Pittsburgh, Pittsburgh, PA) Lewis Kuller; (Wake Forest University School of Medicine, Winston-Salem, NC) Sally Shumaker Women's Health Initiative Memory Study: (Wake Forest University School of Medicine, Winston-Salem, NC) Sally Shumaker, The WHI programs is funded by the National Heart, Lung, and Blood Institute, National Insitutes of Health, U.S. Department of Health and Human Services through contracts, HHSN268201100046C, HHSN268201100001C, HHSN268201100002C, HHSN268201100003C, HHSN268201100004C.

\section{Author details}

${ }^{1}$ Quantitative Sciences Unit, Stanford University School of Medicine, 1070 Arastradero Road, Palo Alto, Stanford, CA 94304, USA. ${ }^{2}$ Stanford Prevention Research Center, Stanford University School of Medicine, Stanford, CA, USA.
${ }^{3}$ Department of Internal Medicine, University of California-Davis, Davis, CA, USA. ${ }^{4}$ Department of Social and Preventive Medicine, University at Buffalo, The State University of New York, Buffalo, NY, USA. ${ }^{5}$ Department of Medicine, Division of General Medical Disciplines, Stanford University School of Medicine, Stanford, CA, USA. ${ }^{6}$ Division of General Internal Medicine and Center for Research on Health Care, University of Pittsburgh, Pittsburgh, PA, USA.

Received: 10 April 2013 Accepted: 19 September 2013

Published: 22 September 2013

\section{References}

1. Hartholt KA, Oudshoorn C, Zielinski SM, Burgers PTPW, Panneman MJM, van Beeck ED, Patka P, van der Cammen TJM: The epidemic of hip fractures: are we on the right track? PLOS ONE 2011, 6:e22227. doi:10.1371/journal. pone.0022227.

2. Stevens JA, Olson S: Reducing falls and resulting hip fractures among older women. MMWR Recommendations and Reports 2000, 49(RR02):1-12.

3. Grønskag AB, Romundstad P, Forsmo S, Langhammer A, Schei B: Excess mortality after hip fracture among elderly women in Norway: the HUNT study. Osteoporosis Int 2011. doi:10.1007/s00198-011-1811-y.

4. Panula J, Philajamäki H, Mattila VM, Jaatinen P, Vahlberg T, Aarnio P, Kivalä SL: Mortality and cause of death in hip fracture patients aged 65 or older: a population-based study. BMC Musculoskelet Disord 2011, 12:105.

5. National Center for Injury Prevention and Control: Hip Fractures Among Older Adults. 2010. http://www.cdc.gov/HomeandRecreationalSafety/Falls/ index.html.

6. Haentjens P, Magaziner J, Colón-Emeric CS, Vanderschueren D, Milisen K, Velkenlers B, Boonen S: Meta-analysis: excess mortality after hip fracture among older women and men. Ann Intern Med 2010, 152:380-390.

7. Burge R, Dawson-Hughes B, Solomon DH, Wong JB, King A, Tosteson A: Incidence and economic burden of osteoporosis-related fractures in the United States, 2005-2025. J Bone Miner Res 2007, 22:465-475.

8. Brauer CA, Coca-Perraillon M, Cutler DM, Rosen AB: Incidence and mortality of hip fractures in the United States. J Am Med Ass 2009, 302:1573-1579.

9. Banks E, Reeves GK, Beral V, Balkwill A, Liu B, Roddam A, Million Women Study Collaborators: Hip fracture incidence in relation to age, menopausal status, and age at menopause: prospective analysis. PLoS Med 2009, 6:1-9.

10. Kim SH, Meehan KP, Blumenfeld T, Szabo RM: Hip Fractures in the United States: 2008 Nationwide Emergency Department Sample. Arthrit Care Res 2012, 64:751-757.

11. De Laet $C$, Kanis JA, Odén A, Johanson H, Johnell O, Delmas P, Eisman JA, Kroger H, Fujiwara S, Garnero P, McCloskey EV, Mellstrom D, Melton LJ 3rd, Meunier P, Pols HA, Reeve J, Silman A, Tenenhouse A: Body mass index as a predictor of fracture risk: a meta-analysis. Osteoporosis Int 2005, 16:1330-1338

12. Stevens JA, Corso PS, Finkelstein EA, Miller TR: The costs of fatal and nonfatal falls among older adults. Inj Prev 2006, 12:290-295.

13. Robbins J, Aragaki AK, Kooperberg C, Watts N, Wactawski-Wende J, Jackson RD, LeBoff MS, Lewis CE, Chen Z, Stefanick ML, Cauley J: Factors associated with 5-year risk of hip fracture in postmenopausal women. J Am Med Ass 2007, 298:2389-2398.

14. Kanis JA, Johnell O, Oden A, Johansson H, De Laet C, Eisman JA, Fujiwara S, Kroger H, McCloskey EV, Mellstrom D, Melton LJ, Pols H, Reeve J, Silman A, Tenenhouse A: Smoking and fracture risk: a meta-analysis. Osteoporosis Int 2005, 16:155-162.

15. Koh WP, Wu AH, Wang R, Ang LW, Heng D, Yuan JM, Yu MC: Genderspecific associations between soy and risk of hip fracture in the Singapore Chinese Health study. Am J Epidemiol 2009, 170:901-909.

16. Feskanich D, Willett W, Colditz G: Walking and leisure-time activity and risk of hip fracture in postmenopausal women. J Am Med Ass 2002, 288:2300-2306.

17. Jackson RD, Donepudi S, Mysiw WJ: Epidemiology of fracture risk in the women's health initiative. Curr Osteoporos Rep 2008, 6:155-161.

18. Berg KM, Kunins HV, Jackson JL, Nahvi S, Chaudhry A, Harris KA, Malik R, Arnsten JH: Association between alcohol consumption and both osteoporotic fracture and bone density. Am J Med 2008, 121:406-418.

19. Høidrup S, Grønbæk M, Gottschau A, Lauritzen JB, Schroll M, Copenhagen Centre for Prospective Population Studies: Alcohol intake, beverage preference, and risk of hip fracture in men and women. Am J Epidemiol 1999, 149:993-1001. 
20. Mukamal KJ, Robbins JA, Cauley JA, Kern LM, Siscovick DS: Alcohol consumption, bone density, and hip fracture among older adults: the cardiovascular health study. Osteoporosis Int 2007, 18:593-602.

21. Wosje KS, Kalkwarf HJ: Bone density in relation to alcohol intake among men and women in the United States. Osteoporosis Int 2007 18:391-400.

22. Cawthon PM, Harrison SL, Barrett-Connor E, Fink HA, Cauley JA, Lewis CE, Orwoll ES, Cummings SR: Alcohol intake and its relationship with bone mineral density, falls, and fracture risk in older men. J Am Geriatr SoC 2006, 54:1649-1657.

23. US Department of Agriculture and US Department of Health and Human Services: Dietary Guidelines for Americans, 2010. Washington, DC: US Government Printing Office; 2010.

24. Grønbæk M, Becker U, Johansen D, Gottschau A, Schnohr P, Hein HO, Jensen G, Sørensen Tl: Type of alcohol consumed and mortality from all causes, coronary heart disease, and cancer. Ann Intern Med 2000, 133:411-419.

25. Klatsky AL, Friedman GD, Armstrong MA, Kipp H: Wine, liquor, beer, and mortality. Am J Epidemiol 2003, 158:585-595.

26. Thun MJ, Peto R, Lopez AD, Monaco JH, Henley SJ, Heath CW Jr, Doll R: Alcohol consumption and mortality among middle-aged and elderly U.S. adults. N Engl J Med 1997, 337:1705-1714

27. Marmot MG, Shipley MJ, Rose G, Thomas BJ: Alcohol and mortality: a UShaped curve. Lancet 1981, 317:580-583.

28. Grønbæk M, Deis A, Sørensen TI, Becker U, Schnohr P, Jensen G: Mortality associated with moderate intakes of wine, beer, or spirits. BMJ 1995, 310:1165-1169.

29. Langer RD, White E, Lewis CE, Kotchen JM, Hendrix SL, Trevisan M: The women's health initiative observational study: Baseline characteristics of participants and reliability of baseline measures. Ann Epidemiol 2003, 13:S107-S121.

30. Prentice R, Rossouw J, Furberg C, Johnson S, Henderson M, Cummings S, Manson J, Freedman L, Oberman A, Kuller L, Anderson G: Design of the WHI clinical trial and observational study. Control Clin Trials 1998, 19:61-109.

31. Patterson RE, Kristal AR, Tinker LF, Carter RA, Bolton MP, Agurs-Collins T: Measurement characteristics of the women's health initiative food frequency questionnaire. Ann Epidemiol 1999, 9:178-187.

32. Jackson RD, LaCroix AZ, Gass M, Wallace RB, Robbins J, Lewis CE, Bassford T, Beresford SA, Black HR, Blanchette P, Bonds DE, Brunner RL, Brzyski RG, Caan B, Cauley JA, Chlebowski RT, Cummings SR, Granek I, Hays J, Heiss G, Hendrix SL, Howard BV, Hsia J, Hubbell FA, Johnson KC, Judd H, Kotchen JM, Kuller LH, Langer RD, Lasser NL, et al: Calcium plus Vitamin D supplementation and the risk of fractures. $N$ Engl J Med 2006, 354:669-683.

33. Curb JD, McTiernan A, Heckbert SR, Kooperberg C, Stanford J, Nevitt M, Johnson KC, Proulx-Burns L, Pastore L, Criqui M, Daugherty S: Outcomes ascertainment and adjudication methods in the women's health initiative. Ann Epidemiol 2003, 13(Suppl 9):S122-S128.

34. Marrone JA, Maddalozzo GF, Branscum AJ, Hardin K, Cialdella-Kam L, Philbrick KA, Breggia AC, Rosen CJ, Turner RT, Iwaniec UT: Moderate alcohol intake lowers biochemical markers of bone turnover in postmenopausal women. Menopause 2012, 19:000-000.

35. Mortensen EL, Jensen HH, Sanders SA, Reinisch JM: Better psychological functioning and higher social status may largely explain the apparent health benefits of wine. Arch Intern Med 2001, 161:1844-1848.

36. Habold C, Momken I, Ouadi A, Bekaert V, Brasse D: Effect of prior treatment with resveratrol on density and structure of rat long bones under tail-suspension. J Bone Miner Metab 2011, 29:15-22.

37. Rayalam S, Della-Fera MA, Baile CA: Synergism between resveratrol and other phytochemicals: Implications for obesity and osteoporosis. $\mathrm{Mol}$ Nutr Food Res 2011, 55:1177-1185.

38. Mukamal KJ, Mittleman MA, Longstreth WT, Newman AB, Fried LP, Siscovick DS: Self-reported alcohol consumption and falls in older adults: crosssectional and longitudinal analyses of the cardiovascular health study. J Am Geriatr Soc 2004, 52:1174-1179.

39. Saad L, Jones J: Gallup Poll Social Series: Consumption Habits. Gallup News Service 2010.

40. Farahmand BY, Persson PG, Michaëlsson K, Baron JA, Parker MG, Ljunghall S: Socioeconomic status, marital status and hip fracture risk: a populationbased case-control study. Osteoporosis Int 2000, 11:803-808.
41. Zingmond DS, Soohoo NF, Silverman SL: The role of socioeconomic status on hip fracture. Osteoporosis Int 2006, 17:1562-1568.

42. Wilson RT, Chase GA, Chrischilles EA, Wallace RB: Hip fracture risk among community-dwelling elderly people in the United States: a prospective study of physical, cognitive, and socioeconomic indicators. Am J Public Health 2006, 96:1210-1218.

43. Vestergaard P, Rejnmark L, Mosekilde L: Socioeconomic aspects of fractures within universal public healthcare: A nationwide case-control study from Denmark. Scand J Public Health 2006, 34:371-377.

44. Quah C, Boulton C, Moran C: The influence of socioeconomic status on the incidence, outcome and mortality of fractures of the hip. $J$ Bone Joint Surg [Br] 2011, 93-B:801-805.

\section{doi:10.1186/1472-6874-13-36}

Cite this article as: Kubo et al:: Preference for wine is associated with lower hip fracture incidence in post-menopausal women. BMC Women's Health 2013 13:36.

\section{Submit your next manuscript to BioMed Central and take full advantage of:}

- Convenient online submission

- Thorough peer review

- No space constraints or color figure charges

- Immediate publication on acceptance

- Inclusion in PubMed, CAS, Scopus and Google Scholar

- Research which is freely available for redistribution 